\section{(6) OPEN ACCESS}

\title{
Restricted fluid bolus volume in early septic shock: results of the Fluids in Shock pilot trial
}

\author{
David Philip Inwald, ${ }^{1}$ Ruth Canter, ${ }^{2}$ Kerry Woolfall, ${ }^{3}$ Paul Mouncey, ${ }^{2}$ Zohra Zenasni, $^{2}$ \\ Caitlin O'Hara, ${ }^{3}$ Anjali Carter, ${ }^{4}$ Nicola Jones, ${ }^{4}$ Mark D Lyttle, ${ }^{\oplus, 6}$ Simon Nadel, $^{1}$ \\ Mark J Peters, ${ }^{7}$ David A Harrison, ${ }^{2}$ Kathryn M Rowan, ${ }^{2}$ on behalf of PERUKI (Paediatric \\ Emergency Research in the UK and Ireland) and PICS SG (Paediatric Intensive Care \\ Society Study Group)
}

\begin{abstract}
- Additional material is published online only. To view please visit the journal online (http://dx.doi.org/10.1136/ archdischild-2018-314924).

For numbered affiliations see end of article.
\end{abstract}

\section{Correspondence to} Dr David Philip Inwald, Paediatric Intensive Care Unit, St Mary's Hospital, Imperial College Healthcare NHS Trust, London SW7 2AZ, UK; d.inwald@imperial.ac.uk

Received 6 February 2018 Revised 10 July 2018 Accepted 15 July 2018 Published Online First 7 August 2018

\section{SLinked}

- http://dx.doi.org/10.1136/ archdischild-2018-315885

Check for updates

(C) Author(s) (or their employer(s)) 2019. Re-use permitted under CC BY. Published by BMJ.

To cite: Inwald DP, Canter $R$, Woolfall K, et al.

Arch Dis Child

2019:104:426-431.

\begin{abstract}
Objective To determine the feasibility of Fluids in Shock, a randomised controlled trial (RCT) of restricted fluid bolus volume $(10 \mathrm{~mL} / \mathrm{kg})$ versus recommended practice $(20 \mathrm{~mL} / \mathrm{kg})$.

Design Nine-month pilot RCT with embedded mixedmethod perspectives study.

Setting 13 hospitals in England.

Patients Children presenting to emergency departments with suspected infection and shock after $20 \mathrm{~mL} / \mathrm{kg}$ fluid.

Interventions Patients were randomly allocated (1:1) to further 10 or $20 \mathrm{~mL} / \mathrm{kg}$ fluid boluses every $15 \mathrm{~min}$ for up to 4 hours if still in shock.
\end{abstract}

Main outcome measures These were based on progression criteria, including recruitment and retention, protocol adherence, separation, potential trial outcome measures, and parent and staff perspectives.

Results Seventy-five participants were randomised; two were withdrawn. $23(59 \%)$ of 39 in the $10 \mathrm{~mL} / \mathrm{kg}$ arm and $25(74 \%)$ of 34 in the $20 \mathrm{~mL} / \mathrm{kg}$ arm required a single trial bolus before the shock resolved. $79 \%$ of boluses were delivered per protocol in the $10 \mathrm{~mL} / \mathrm{kg}$ arm and $55 \%$ in the $20 \mathrm{~mL} / \mathrm{kg}$ arm. The volume of study bolus fluid after 4 hours was $44 \%$ lower in the $10 \mathrm{~mL} / \mathrm{kg}$ group (mean 14.5 vs $27.5 \mathrm{~mL} / \mathrm{kg}$ ). The Paediatric Index of Mortality-2 score was 2.1 (IQR 1.6-2.7) in the $10 \mathrm{~mL} / \mathrm{kg}$ group and 2.0 (IQR $1.6-2.5)$ in the $20 \mathrm{~mL} / \mathrm{kg}$ group. There were no deaths. Length of hospital stay, paediatric intensive care unit (PICU) admissions and PICU-free days at 30 days did not differ significantly between the groups. In the perspectives study, the trial was generally supported, although some problems with protocol adherence were described.

Conclusions Participants were not as unwell as expected. A larger trial is not feasible in its current design in the UK. Trial registration number ISRCTN 15244462.

\section{BACKGROUND}

Rapid, bolus fluid resuscitation is integral to the management of children presenting with septic shock. The 2009 American College of Critical Care Medicine-Pediatric Advanced Life Support (ACCM-PALS) clinical guideline recommended fluid resuscitation with boluses of $20 \mathrm{~mL} / \mathrm{kg}$, up to a total of $200 \mathrm{~mL} /$ $\mathrm{kg}$ in the first hour. ${ }^{1}$ However, this recommendation is now controversial; it was based on retrospective observational studies, some involving small numbers of children, ${ }^{2-4}$ and audit data have shown that the recommendations are often not followed. ${ }^{5}$
What is already known on this topic?

- Rapid, liberal fluid bolus resuscitation is integral to the management of children presenting to emergency departments with septic shock.

- No trials have compared a more restricted fluid bolus resuscitation strategy with the currently recommended strategy in high-income countries.

- The optimal amount of fluid for resuscitation for children presenting with septic shock in highincome countries is an important unanswered question.

\section{What this study adds?}

- The Fluids in Shock (FiSh) pilot compared a restricted fluid bolus volume $(10 \mathrm{~mL} / \mathrm{kg})$ with the current recommendation $(20 \mathrm{~mL} / \mathrm{kg})$ to determine the feasibility of a large-scale trial.

- A larger FiSh trial is not feasible; participants had a lower severity of illness than expected.

- Further observational work is required to determine the epidemiology of severe childhood infection in the UK in the postvaccine era.

In Africa, a multicentre randomised controlled trial (RCT), the Fluid Expansion as Supportive Therapy (FEAST) trial, compared bolus fluid resuscitation of $20 \mathrm{~mL} / \mathrm{kg}$ with maintenance fluid in over 3000 children with severe infection. ${ }^{6}$ The study reported 35\% higher mortality associated with bolus fluid resuscitation. Although conducted in Africa in a low-income setting, the FEAST trial highlighted the lack of evidence for bolus fluid resuscitation for children in middle-income and high-income settings. ${ }^{78}$

No trial has compared restricted bolus fluid resuscitation strategy with recommended bolus fluid resuscitation in children with septic shock in high-income countries. In the UK, children presenting to emergency departments (EDs) with severe sepsis and discussed with a paediatric intensive care retrieval service have a reported mortality of up to $17 \%{ }^{9}$ With emerging data suggesting that excessive fluid administration is associated with worse outcomes in paediatric intensive care unit (PICU), ${ }^{10-14}$ the optimal 
amount of fluid for resuscitation for children presenting with septic shock remains an important unanswered question.

To address this problem, the Fluids in Shock (FiSh) trial was developed, which aimed to evaluate whether a restricted fluid bolus volume $(10 \mathrm{~mL} / \mathrm{kg})$, compared with currently recommended fluid bolus volume $(20 \mathrm{~mL} / \mathrm{kg})$, is associated with improved outcomes for children presenting to UK EDs with presumed septic shock. Our initial qualitative feasibility study results have been reported previously. ${ }^{15}$ This paper reports the results of the external pilot trial and embedded parent and staff perspectives study.

\section{METHODS}

\section{Study design}

The study design was a pragmatic, open, multicentre pilot RCT. The pilot trial was sponsored by the Imperial College Healthcare NHS Trust and coordinated by the Intensive Care National Audit \& Research Centre Clinical Trials Unit (CTU). The ISRCTN trial registration number is 15244462 . The protocol is available at https://www.journalslibrary.nihr.ac.uk/programmes/hta/ 1304105/\#/.

\section{Pilot trial}

Sites and participants

Sites were set up in a 'hub and spoke' model in three regions in England. The 'hubs' were four regional hospitals with PICUs (two hospitals covered the same region), three of which also had an integrated ED. The 'spokes' were nine district general hospitals with an ED but not a PICU linked to the 'hub' PICU by the regional PICU retrieval service. Participating EDs were research-active sites and part of the Paediatric Emergency Research in the United Kingdom \& Ireland network. ${ }^{16}$ Extensive training was provided for the site teams, including a site initiation visit from the CTU and local training of clinical staff by their own research staff.

The inclusion criteria were age older than 37 weeks (corrected gestational age) and younger than 16 years; clinical suspicion of infection; and signs of shock-defined as age-adjusted hypotension (less than fifth centile systolic blood pressure (BP) for age or capillary refill time (CRT) greater than or equal to $3 \mathrm{~s}$ )-after receipt of $20 \mathrm{~mL} / \mathrm{kg}$ of bolus fluid. Fifth centile systolic BP was provided to sites in age bands on wallet-sized cards for quick reference ( $<1$ week: $<60 \mathrm{~mm} \mathrm{Hg}$; 1 week to $<1$ year: $<70 \mathrm{~mm} \mathrm{Hg}$; 1 to $<2$ years: $<75 \mathrm{~mm} \mathrm{Hg} ; 2$ to $<5$ years: $<80 \mathrm{~mm} \mathrm{Hg}$; 5 to $<12$ years: $<85 \mathrm{~mm} \mathrm{Hg}$; and $\geq 12$ years: $<90 \mathrm{~mm} \mathrm{Hg}$ ). The exclusion criteria were prior receipt of more than $20 \mathrm{~mL} / \mathrm{kg}$ of bolus fluid; conditions in which bolus fluid resuscitation should be curtailed; or full active resuscitation not within the current goals of care.

\section{Randomisation and trial intervention}

Eligible patients were randomised while in an acute assessment area (eg, paediatric assessment unit or ED) and allocated 1:1 to either $10 \mathrm{~mL} / \mathrm{kg}$ or $20 \mathrm{~mL} / \mathrm{kg}$ boluses over a 4-hour resuscitation period, without prior consent. The resuscitation period was divided into $15 \mathrm{~min}$ cycles, with one bolus of either $10 \mathrm{~mL} / \mathrm{kg}$ or $20 \mathrm{~mL} / \mathrm{kg}$ to be delivered in each cycle. The maximum amount of fluid that could be given per bolus was either $500 \mathrm{~mL}$ (for those allocated to $10 \mathrm{~mL}$ / $\mathrm{kg}$ boluses) or $1000 \mathrm{~mL}$ (for those allocated to $20 \mathrm{~mL} / \mathrm{kg}$ boluses). Fluid type and other interventions were left to the discretion of the treating clinician. At the end of each cycle, if age-adjusted signs of shock persisted, then another bolus of the same size was given within the next 15 min cycle.

In participants whose shock resolved or who showed signs of fluid overload (pulmonary oedema-rales on auscultation or pulmonary oedema fluid in the endotracheal tube-or new or increasing hepatomegaly), delivery of further fluid boluses was withheld. If, within the 4-hour resuscitation period, fluid boluses were indicated, that is, signs of shock were present in the absence of signs of fluid overload, cycles were recommenced with allocated boluses until the end of the 4-hour intervention period. After this period, any further treatment was at the discretion of the treating clinician.

The maximum amount of fluid that could be given within the pilot trial protocol, regardless of allocation, was $120 \mathrm{~mL} / \mathrm{kg}$ (excluding the $20 \mathrm{~mL} / \mathrm{kg}$ bolus prerandomisation).

\section{Consent}

A member of the site research team approached parents/legal representatives as soon as appropriate after randomisation to take consent for use of study data, according to the guidance developed in the FiSh feasibility study ${ }^{15}$ and elsewhere. ${ }^{17-21}$ This is known as research without prior consent (RWPC), a methodology favoured in emergency care trials. ${ }^{22}$ Specific FiSh RWPC methodology was developed during the feasibility study ${ }^{15}$ for all possible situations, including early discharge or death of the participant.

\section{Outcome measures}

The objectives of the pilot trial were to test if the processes worked together, and to inform the design and conduct of the full FiSh trial (should this be the recommendation from the pilot). Outcome measures were driven by the progression criteria to be assessed by the pilot, and included recruitment and retention, protocol adherence and demonstration of separation between the groups, distribution of potential trial outcome measures, and parent and staff perspectives.

These were determined by the proportion of eligible participants recruited, number of participants recruited per site per month, proportion of parents/legal representatives refusing consent, proportion of fluid boluses delivered at the correct volume and time during the intervention period (at least $80 \%$ of bolus fluid resuscitation delivered at correct volume and timing $\pm 10 \%$ ), total volume of fluid received during the intervention period in each treatment group (absolute total volume of fluid administered during the first hour and first 4 hours is lower (by at least 25\%) in the $10 \mathrm{~mL} / \mathrm{kg}$ group), characteristics of potential outcome measures and observed adverse events, and parent and staff perspectives.

Data collection was via a secure, dedicated, electronic database. Sites collected data throughout each patient's hospital admission on the inclusion criteria, baseline-including the Paediatric Index of Mortality (PIM2r; the recalibrated version of PIM2 score, a PICU severity of illness score giving a population risk of mortality $)^{24} 25$ interventions, physiology, location of care to hospital discharge and survival at day 30 . For participants admitted to PICU, daily organ support data were obtained via linkage with the Paediatric Intensive Care Audit Network, the UK national clinical audit for paediatric intensive care.

\section{Statistical analysis}

The trial was set up as a small pilot RCT without a defined primary outcome, and hence without a usual power calculation to determine sample size. Instead, sample size was determined to be adequate to estimate the parameters to be tested. ${ }^{26}$ Based on available data, it was anticipated that the 12 EDs would recruit approximately one participant per month, that is, 108 participants over 9 months.

All statistical analyses were documented a priori in a Statistical Analysis Plan (available from https://www.icnarc.org/Our-Research/ Studies/Fish/Study-Documents). Statistical analyses were based on the intention-to-treat principle. All tests used were two-sided with 
significance levels set at $\mathrm{p}<0.05$ and with no adjustment for multiplicity. Final analyses were conducted using Stata/SE V.14.0.

\section{Embedded perspectives study}

This was a mixed-method study which aimed to explore parent and staff experiences and views of the pilot trial. The participants were pilot trial site staff and parents of randomised children. The questionnaire and topic guides were developed using previous research ${ }^{17}$ and feasibility study findings. ${ }^{15}$ Quantitative data were collected from the focus groups via a keypad voting system, alongside audio-recorded qualitative discussions. Informed consent was taken. Interviews continued until no new themes were identified, that is, data saturation was reached. ${ }^{27}$ Qualitative data analysis was performed according to the methodology outlined in the feasibility study. ${ }^{14}$ Quantitative data were analysed using simple descriptive statistics. Data synthesis was pragmatic and drew on the constant comparative approach. ${ }^{28} 29$

\section{RESULTS}

Pilot trial

Sites, participants and recruitment

The pilot trial was conducted in 13 hospitals from July 2016 to April 2017, with follow-up completed on 31 May 2017. In total, 297 patients who had received a fluid bolus of any size were screened. Eighty-eight (29.8\%) received a fluid bolus of less than $20 \mathrm{~mL} / \mathrm{kg}$, while $108(51.7 \%)$ did not meet the defined clinical signs of shock after receiving $20 \mathrm{~mL} / \mathrm{kg}$. There were $18(17.8 \%)$ patients who met one or more exclusion criteria.

Overall, 75 (90.4\%) out of 83 eligible patients were recruited, 40 into the $10 \mathrm{~mL} / \mathrm{kg}$ group and 35 into the $20 \mathrm{~mL} / \mathrm{kg}$ group.
Two were withdrawn (figure 1) as the parents/legal representatives could not be approached for informed consent. The overall recruitment rate was 0.9 participants per site per month $(95 \%$ CI 0.7 to 1.2), although the majority of recruitment was led by three sites. Recruitment was stopped at the end of the prespecified 9-month period from first site opening.

Baseline characteristics were well matched, although there was some imbalance in age and consequently in weight (table 1). The majority of participants met the shock criteria of CRT $\geq 3 \mathrm{~s}$ (76.9\% in $10 \mathrm{~mL} / \mathrm{kg}$ group, $88.2 \%$ in $20 \mathrm{~mL} / \mathrm{kg}$ group). The PIM2r score was balanced across treatment groups but was lower than expected. The mean PIM2r score was 2.1\%.

Thirty-seven participants $(51.3 \%$ in $10 \mathrm{~mL} / \mathrm{kg}$ group, $50 \%$ in $20 \mathrm{~mL} / \mathrm{kg}$ group) had infection confirmed by the site team, that is, positive bacterial, viral or fungal microscopy, culture, PCR or immunofluorescence test. However, in five of these, the organism was not recorded. Of the remaining 32, 13 had bacterial infections in sterile sites (table 1), only one of which was vaccine-preventable. There were 18 viral infections, most of which were respiratory pathogens. One patient had falciparum malaria.

\section{Adherence to protocol and separation}

All participants randomised to the $20 \mathrm{~mL} / \mathrm{kg}$ group received their first bolus. Three participants randomised to the $10 \mathrm{~mL} / \mathrm{kg}$ group did not receive their first bolus, although correctly identified as in shock, because it was deemed they no longer required fluid postrandomisation. Of the subsequent boluses, one participant in the $20 \mathrm{~mL} / \mathrm{kg}$ group was administered a bolus when the shock criteria were not met. Five participants in total (three from the

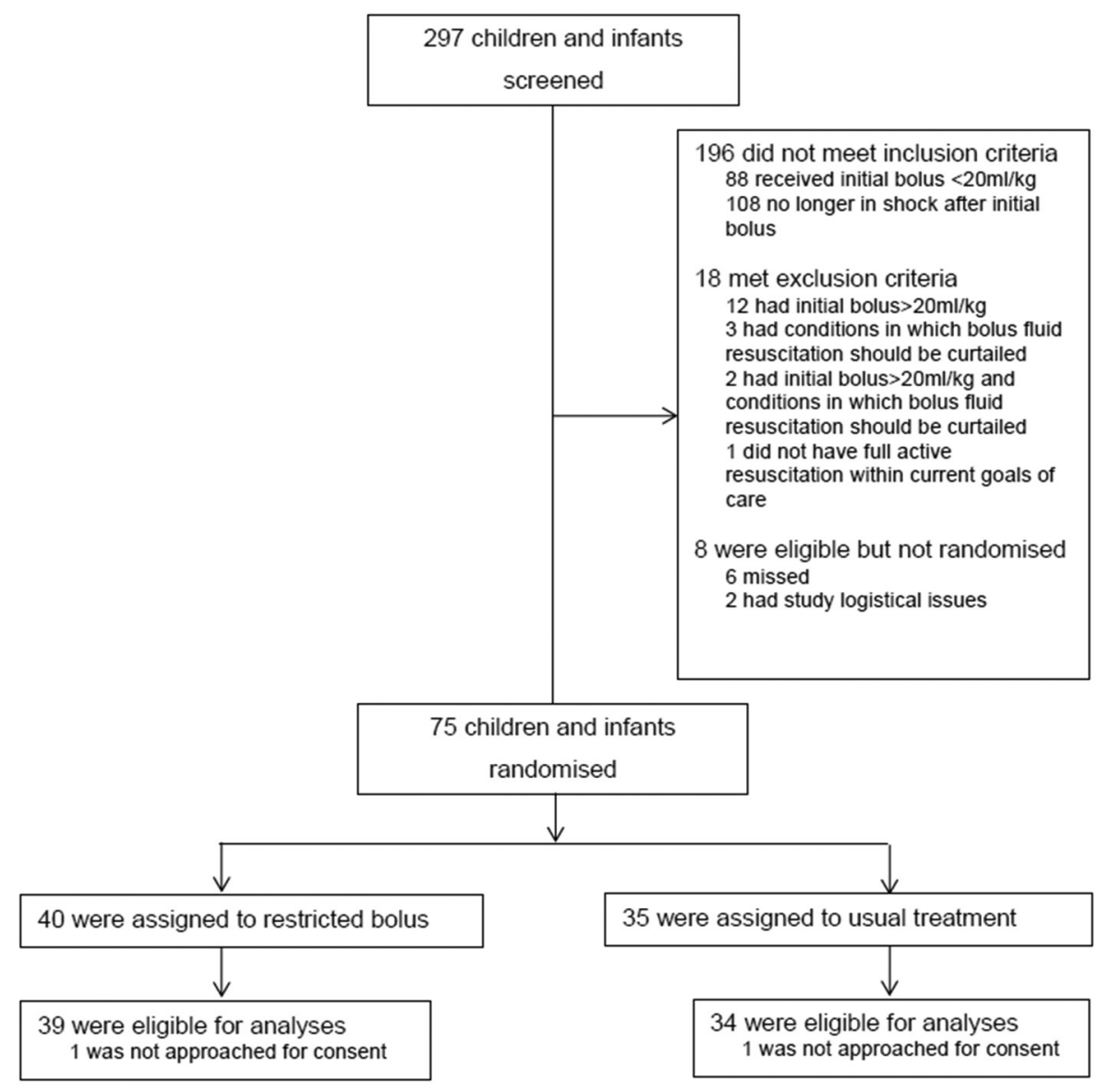

Figure 1 Consolidated Standards of Reporting Trials flow diagram. 


\begin{tabular}{|c|c|c|}
\hline Characteristics & $\begin{array}{l}10 \mathrm{~mL} / \mathrm{kg} \\
(\mathrm{n}=39)\end{array}$ & $\begin{array}{l}20 \mathrm{~mL} / \mathrm{kg} \\
(\mathrm{n}=34)\end{array}$ \\
\hline \multicolumn{3}{|l|}{ Age (months) } \\
\hline Median (IQR) & $11(1-35)$ & $2(1-17)$ \\
\hline \multicolumn{3}{|l|}{ Gender, $\mathrm{n}(\%)$} \\
\hline Male & $24(61.5)$ & $18(52.9)$ \\
\hline Female & $15(38.5)$ & $16(47.1)$ \\
\hline \multicolumn{3}{|l|}{ Weight (kg) } \\
\hline Median (IQR) & $9(5-13)$ & $5(4-10)$ \\
\hline \multicolumn{3}{|l|}{ Shock criteria met, n (\%) } \\
\hline $\mathrm{CRT}^{*}$ only & $30(76.9)$ & $30(88.2)$ \\
\hline Hypotension only & $2(5.1)$ & $2(5.9)$ \\
\hline $\mathrm{CRT}^{*}$ and hypotension & $1(2.6)$ & $2(5.9)$ \\
\hline Neither & $6(15.4)$ & $0(0.0)$ \\
\hline \multicolumn{3}{|l|}{ Systolic BP (mm Hg) } \\
\hline Median (IQR) & $102(91-114)$ & $104(89-115)$ \\
\hline \multicolumn{3}{|l|}{ CRT (s) } \\
\hline Median (IQR) & $3(3-4)$ & $3(3-4)$ \\
\hline \multicolumn{3}{|l|}{ PIM2r (2016) score (\%) } \\
\hline Median (IQR) & $2.1(1.6-2.7)$ & $2.0(1.6-2.5)$ \\
\hline \multicolumn{3}{|l|}{ Infection confirmed, $\mathrm{n}(\%)$} \\
\hline No & $19(48.7)$ & $17(50.0)$ \\
\hline Yes & $20(51.3)$ & $17(50.0)$ \\
\hline \multicolumn{3}{|l|}{ Organism } \\
\hline Bacterial, n (\%) & $5(31.3)$ & $8(50.0)$ \\
\hline Escherichia coli & $1(6.3)$ & $4(25.0)$ \\
\hline Enterococcus faecalis & $2(12.5)$ & $0(0.0)$ \\
\hline Group A streptococcus & $1(6.3)$ & $1(6.3)$ \\
\hline Group B streptococcus & $0(0.0)$ & $1(6.3)$ \\
\hline Staphylococcus aureus & $1(6.3)$ & $0(0.0)$ \\
\hline Meningococcus & $0(0.0)$ & $1(6.3)$ \\
\hline Gram-positive coccus (unspecified) & $0(0.0)$ & $1(6.3)$ \\
\hline Viral, n (\%) & $10(62.5)$ & $8(50.0)$ \\
\hline Respiratory syncytial virus & $5(31.3)$ & $3(18.8)$ \\
\hline Rhinovirus & $2(12.5)$ & $3(18.8)$ \\
\hline Influenza A & $0(0.0)$ & $1(6.3)$ \\
\hline Metapneumovirus & $1(6.3)$ & $0(0.0)$ \\
\hline Enterovirus & $1(6.3)$ & $1(6.3)$ \\
\hline Rotavirus & $1(6.3)$ & $0(0.0)$ \\
\hline Others, n (\%) & $1(6.3)$ & $0(0.0)$ \\
\hline Falciparum malaria & $1(6.3)$ & $0(0.0)$ \\
\hline
\end{tabular}

${ }^{*} \mathrm{CRT} \geq 3 \mathrm{~s}$.

BP, blood pressure; CRT, capillary refill time; PIM2r, Paediatric Index of Mortality, recalibrated version.

$10 \mathrm{~mL} / \mathrm{kg}$ group and two from the $20 \mathrm{~mL} / \mathrm{kg}$ group) who met the shock criteria did not receive the designated fluid bolus (table 2).

The majority of participants in both groups received one fluid bolus, $23(59 \%)$ in the $10 \mathrm{~mL} / \mathrm{kg}$ group and $25(74 \%)$ in the $20 \mathrm{~mL} / \mathrm{kg}$ group. During the total 4-hour intervention period, only four patients received four or more fluid boluses. Seventy per cent of participants required only one study fluid bolus and only $11 \%$ required more than two study boluses.

Assessment of the separation progression criteria showed that the mean total volume of study fluid given during the first hour was $38 \%$ lower (13.5 vs $20.7 \mathrm{~mL} / \mathrm{kg}$ ) and during the entire 4-hour intervention period was $44 \%$ lower (mean $14.5 \mathrm{vs} 27.5 \mathrm{~mL} / \mathrm{kg}$ ) in the $10 \mathrm{~mL} / \mathrm{kg}$ group compared with the $20 \mathrm{~mL} / \mathrm{kg}$ group. At the end of the 4-hour intervention period, this corresponded to a
Table 2 Protocol deviations by treatment group

\begin{tabular}{llll}
\hline Variables & & $\begin{array}{l}10 \mathrm{~mL} / \mathrm{kg} \\
(\mathrm{n}=39)\end{array}$ & $\begin{array}{l}20 \mathrm{~mL} / \mathrm{kg} \\
(\mathrm{n}=34)\end{array}$ \\
\hline Did not receive first bolus & Patients, $\mathrm{n}(\%)$ & $3(7.7)$ & $0(0.0)$ \\
Of subsequent boluses & & & \\
Bolus given, shock criteria not met & $\begin{array}{l}\text { Deviations, } \mathrm{n} \\
\text { Shock criteria met, no bolus given }\end{array}$ & 0 & 1 \\
& Patients, $\mathrm{n}(\%)$ & $0(0.0)$ & $1(2.9)$ \\
& $\begin{array}{l}\text { Deviations, } \mathrm{n} \\
\text { Patients, } \mathrm{n}(\%)\end{array}$ & $3(7.7)$ & 2 \\
& & & \\
\hline
\end{tabular}

statistically significant mean difference of $-11.2 \mathrm{~mL} / \mathrm{kg}(95 \% \mathrm{CI}$ -16.6 to $-5.8 \mathrm{~mL} / \mathrm{kg} ; \mathrm{p}<0.001)$. With regard to the adherence progression criteria, overall, 37 (78.7\%) of 47 boluses were delivered at the correct volume and within $15 \mathrm{~min}$ in the $10 \mathrm{~mL} / \mathrm{kg}$ group, whereas $24(54.5 \%)$ of 44 boluses were delivered at the correct volume and within $15 \mathrm{~min}$ in the $20 \mathrm{~mL} / \mathrm{kg}$ group (table 3 ).

Potential outcome measures for a future trial

There were no deaths and no serious adverse events reported. Two patients in the $20 \mathrm{~mL} / \mathrm{kg}$ group developed signs of fluid overload after the first study bolus, and consequently did not

\begin{tabular}{|c|c|c|}
\hline Variables & $10 \mathrm{~mL} / \mathrm{kg}$ & $20 \mathrm{~mL} / \mathrm{kg}$ \\
\hline Patients, $\mathrm{n}$ & 39 & 34 \\
\hline \multicolumn{3}{|c|}{ Number of study boluses delivered, $\mathrm{n}(\%)$ of patients } \\
\hline 0 & $3(7.7)$ & $0(0.0)$ \\
\hline 1 & $23(59.0)$ & $25(73.5)$ \\
\hline 2 & $8(20.5)$ & $6(17.6)$ \\
\hline 3 & $3(7.7)$ & $1(2.9)$ \\
\hline 4 or more & $2(5.1)$ & $2(5.9)$ \\
\hline \multicolumn{3}{|c|}{ Total volume of study fluid received during the first hour $(\mathrm{mL} / \mathrm{kg})^{*}$} \\
\hline Mean (SD) & $13.5(8.0)$ & $20.7(8.3)$ \\
\hline \multicolumn{3}{|c|}{ Total volume of study fluid received during the intervention period $(\mathrm{mL} / \mathrm{kg})^{*}$} \\
\hline Mean (SD) & $14.5(11.1)$ & $25.7(12.0)^{*}$ \\
\hline Total number of boluses delivered $t$ & 58 & 48 \\
\hline \multicolumn{3}{|l|}{ Volume of study bolus, $n(\%)$ of boluses } \\
\hline$<10 \mathrm{~mL} / \mathrm{kg} \ddagger$ & $2(3.4)$ & $3(6.3)$ \\
\hline $10 \mathrm{~mL} / \mathrm{kg} \dagger$ & $56(96.6)$ & $5(10.4)$ \\
\hline $20 \mathrm{~mL} / \mathrm{kg} \dagger$ & $0(0.0)$ & $40(83.3)$ \\
\hline \multicolumn{3}{|c|}{ Timing of delivery of study bolus, $n(\%)$ of boluses§ } \\
\hline$\leq 15 \min$ & $38(80.9)$ & $30(68.2)$ \\
\hline $16-20 \mathrm{~min}$ & $7(14.9)$ & $5(11.4)$ \\
\hline $21-30 \mathrm{~min}$ & $2(4.3)$ & $1(2.3)$ \\
\hline$>30 \min$ & $0(0.0)$ & $8(18.2)$ \\
\hline \multicolumn{3}{|c|}{ Delivery of study bolus with 15 min by age group, $\mathrm{n}(\%)$ of boluses $¥$} \\
\hline$<1$ year & $24 / 27(88.9)$ & $22 / 29(75.9)$ \\
\hline 1 to $<2$ years & $7 / 9(77.8)$ & $2 / 3(66.7)$ \\
\hline 2 to $<5$ years & $6 / 7(85.7)$ & $2 / 4(50.0)$ \\
\hline$\geq 5$ years & $1 / 4(25.0)$ & $4 / 8(50.0)$ \\
\hline \multicolumn{3}{|c|}{$\begin{array}{l}\text { Study fluid boluses delivered at the correct volume and within } 15 \mathrm{~min}, \mathrm{n}(\%) \text { of } \\
\text { boluses: }\end{array}$} \\
\hline No & $10(21.3)$ & $20(45.5)$ \\
\hline Yes & $37(78.7)$ & $24(54.5)$ \\
\hline \multicolumn{3}{|c|}{$\begin{array}{l}\text { * } P<0.001 \text { ( } t \text {-test). } \\
\dagger \text { All study boluses were of normal saline except } 4 \text { of plasmalyte and } 4 \text { of } \\
\text { Hartmann's solution. } \\
\ddagger \pm 10 \% \text {. } \\
\S \text { Timing of delivery not reported for } 15 \text { boluses ( } 11 \text { in } 10 \mathrm{~mL} / \mathrm{kg} \text { group, } 4 \mathrm{in} 20 \mathrm{~mL} / \\
\mathrm{kg} \text { group). }\end{array}$} \\
\hline
\end{tabular}


receive a second bolus despite remaining in shock. Overall, 29\% participants were admitted to PICU. As expected in this small pilot trial, length of hospital stay, transfers to PICU, length of stay in PICU and days alive and free of PICU to 30 days did not differ significantly between the groups (table 4).

\section{Embedded perspectives study}

A total of $52(69 \%)$ of 75 parents of randomised participants provided consent to complete a questionnaire or take part in a telephone interview. Of these, 45 (87\%) parents (34 mothers, 11 fathers) from 44 families completed a questionnaire before leaving the hospital. Data saturation was reached at $20(38 \%)$ of 52 interviews with parents (19 mothers, 1 father; 26.5 (median) days since child's admission). There were three pilot trial 'hub' site focus groups (20 staff) and telephone interviews with 7 (35\%) of 20 invited staff (until data saturation point), including 14 (52\%) of 27 nurses and 13 (48\%) of 27 doctors from 7 (58\%) of 12 sites (for thematic analysis, see online supplementary file).

Interview and questionnaire data indicated some parents were surprised to discover that their child had been enrolled into the pilot trial without prior informed consent (online supplementary file). However, clear explanations from site staff about RWPC and the nature of the intervention appeared to elicit parental support.

Site training had prepared staff for recruitment and RWPC. The randomisation method was viewed as straightforward. However, some clinical staff found it difficult to complete the case report form while treating a child. Staff also described problems adhering to the protocol, including administering $20 \mathrm{~mL} / \mathrm{kg}$ boluses within the 15 min cycles and a lack of equipoise among a minority of clinicians when a child had been randomised to a $20 \mathrm{~mL} / \mathrm{kg}$ allocation due to concerns about fluid overload.

\section{DISCUSSION}

The pilot trial was successfully conducted. Screening logs showed that over $90 \%$ of eligible patients were randomised across the study sites over the study period with a recruitment rate of 0.9 participants per site per month, very close to the anticipated recruitment rate of 1 per site per month.

However, the sites opened over a 4-month period rather than all at once, reducing the anticipated recruitment total from 108 to 84 . Recruitment was driven mainly by three study sites, which recruited 38 of the 75 participants. A staggered opening of sites would be needed in the design for a larger FiSh trial, targeting sites most likely to see a high number of eligible patients.
The process of RWPC worked smoothly, with no parents refusing consent. This is likely due to the bespoke FiSh RWPC methodology, developed during the feasibility study. ${ }^{15}$ No participants died during the course of the study, so the procedures to follow in the event of a child's death were not tested.

The intervention was delivered according to protocol in the majority of participants. Adherence to volume and timing was close to achieving the $80 \%$ progression criteria target in the $10 \mathrm{~mL} / \mathrm{kg}$ group but was not as good in the $20 \mathrm{~mL} / \mathrm{kg}$ group. This appeared to be due to the difficulty in delivering the $20 \mathrm{~mL} / \mathrm{kg}$ bolus within the $15 \mathrm{~min}$ time frame, especially in the period immediately postrandomisation. There was also some suggestions from the embedded perspectives study, indicating that some clinicians lacked equipoise, favouring $10 \mathrm{~mL} / \mathrm{kg}$ over $20 \mathrm{~mL} / \mathrm{kg}$ fluid boluses, despite the recently updated ACCMPALS guidance continuing to recommend $20 \mathrm{~mL} / \mathrm{kg}$ boluses. ${ }^{30}$ Despite these challenges, good separation between the groups was achieved, with volume of fluid delivered (in $\mathrm{mL} / \mathrm{kg}$ ) 35\% lower in the first hour and 44\% lower over the entire 4-hour period in the $10 \mathrm{~mL} / \mathrm{kg}$ group. If a larger trial were feasible, the resuscitation algorithm could be modified to improve adherence by allowing for longer periods to deliver study boluses.

Though the trial processes were deemed feasible, the population had lower severity of illness than expected from previous data 9 , impacting on the feasibility of a larger study. This may be a consequence of the inclusion criteria being too lax in the context of an increasingly immunised population. A recent Europe-wide study demonstrated that the disease burden of severe childhood infection is mainly in children younger than 5 years and is largely due to vaccine-preventable meningococcal and pneumococcal infections. ${ }^{31}$ However, in the UK, the childhood vaccination programme has resulted in massive reductions in the incidence of both group $\mathrm{B}$ meningococcal disease ${ }^{32}$ and invasive pneumococcal disease. ${ }^{33}$ Indeed, only one patient recruited into the FiSh pilot trial had a vaccine-preventable infection. Thus, if the FiSh inclusion criteria were to be changed to restrict to more severely ill children, then the number of eligible children would inevitably be reduced, impacting on the likelihood of completing a large-scale trial in an acceptable time frame in the UK.

A recent systematic review ${ }^{34}$ identified only one RCT, other than FEAST, which investigated different-sized fluid bolus therapy in children in septic shock. ${ }^{35}$ However, this was a small, single-centre study in India. Thus, at the time of writing, the optimum strategy for fluid bolus resuscitation in children with septic shock in high-income countries remains unknown.

Table 4 Potential outcome measures by treatment group

\begin{tabular}{|c|c|c|c|}
\hline Potential outcome measures & $\begin{array}{l}10 \mathrm{~mL} / \mathrm{kg} \\
(\mathrm{n}=39)\end{array}$ & $\begin{array}{l}20 \mathrm{~mL} / \mathrm{kg} \\
(\mathrm{n}=34)\end{array}$ & $\begin{array}{l}\text { Difference } \\
(95 \% \mathrm{Cl})\end{array}$ \\
\hline Hospital mortality, n/N (\%) & $0 / 39(0.0)$ & $0 / 34(0.0)$ & NA \\
\hline Length of hospital stay (days), median (IQR) (N) & $4(3-7)(39)$ & $5(4-8)(34)$ & $-1(-2.5$ to 0.5$)$ \\
\hline Transferred to PICU, n/N (\%) & $10 / 39(25.6)$ & $11 / 34(32.4)$ & $-6.7(-27.6$ to 14.1$)$ \\
\hline Length of stay in PICU (hours), median (IQR) (N) & $45(18-143)(10)$ & $119(52-228)(11)$ & $-65(-171$ to 41$)$ \\
\hline Days alive and free of PICU up to 30 days postrandomisation, mean (SD) (N) & $28.9(2.4)(39)$ & $27.9(3.6)(34)$ & $1.0(-0.4$ to 2.4$)$ \\
\hline Receipt of mechanical ventilation, $\mathrm{n} / \mathrm{N}^{*}(\%)$ & $4 / 36(11.1)$ & $8 / 32(25.0)$ & $-13.9(-32.1$ to 4.3$)$ \\
\hline Duration of mechanical ventilation (days), median (IQR) $(\mathrm{N})^{*}$ & $6(4-8)(4)$ & $5.5(4-8.5)(8)$ & $0(-5.9$ to 5.9$)$ \\
\hline Days alive and free of mechanical ventilation up to 30 days postrandomisation, mean (SD) (N)* & $29.3(2.1)(36)$ & $28.5(2.7)(32)$ & $0.8(-0.4$ to 2.0$)$ \\
\hline Receipt of inotropes, $\mathrm{n} / \mathrm{N}^{*}(\%)$ & $1 / 36(2.8)$ & $5 / 32(15.6)$ & $-12.8(-26.5$ to 0.8$)$ \\
\hline Mortality at 30 days postrandomisation, $\mathrm{n} / \mathrm{N}(\%)$ & $0 / 39(0.0)$ & $0 / 34(0.0)$ & NA \\
\hline
\end{tabular}

${ }^{*}$ Organ support data missing for three patients in the $10 \mathrm{~mL} / \mathrm{kg}$ group and two patients in the $20 \mathrm{~mL} / \mathrm{kg}$ group transferred to PICUs not participating in the pilot trial. NA, not available; PICU, paediatric intensive care unit. 


\section{CONCLUSIONS}

A larger FiSh trial, with the current design, and in the UK, is not feasible. Further observational research is required to determine the epidemiology of severe childhood infection in the UK in the postvaccine era.

\section{Author affiliations}

${ }^{1}$ Paediatric Intensive Care Unit, St Mary's Hospital, Imperial College Healthcare London NHS Trust, London, UK

${ }^{2}$ Clinical Trials Unit, Intensive Care National Audit \& Research Centre, London, UK

${ }^{3}$ Department of Psychological Sciences, North West Hub for Trials Methodology, University of Liverpool, Liverpool, UK

${ }^{4}$ Parent representative

${ }^{5}$ Faculty of Health and Applied Sciences, University of the West of England, Bristol,

${ }^{6}$ Emergency Department, Bristol Royal Hospital for Children, Bristol, UK ${ }^{7}$ Respiratory, Critical Care and Anaesthesia Section, Institute of Child Health, University College London Great Ormond Street, London, UK

Acknowledgements We wish to thank all the patients and staff from all the sites that participated in the trial. It is impossible to thank everyone personally; however, we would like to thank the following research staff: ICNARC (Nick Hudson, Steve Saunders); Bristol Royal Hospital for Children (Pauline Jackson, Anna Laskey, Alice Smith); Chelsea and Westminster Hospital (Sara Edwards, Victoria Wilson, Hester Yorke); Great Ormond Street Hospital for Children (Lauran O'Neill, Fran Standing); Musgrove Park Hospital (Debs Heard, Jayne Foot, Esther Wilson); Northwick Park Hospital (Sathish Bangalore, Katie Blundell); Queen Alexandra Hospital (Simon Birch, Alan Charters, Zoe Daly, Kat Ellinor); Royal Devon and Exeter Hospital (Caroline Harrill, Nicola Jones, Simon Parke, Jennie Small, Su Wilkins); Royal United Hospital (Elizabeth Gilby, Anna Wedgwood); Salisbury District Hospital (Jim Baird, Nick Brown, Sarah Diment, Dee Mead); Southampton General Hospital (Jane Bayreuther, Ruth Ensom, Lisa Fairhead, John Pappachan); St Mary's Hospital (Rikke Joergensen, Farhana Abdulla, Salina Persand); Watford General Hospital (Solomon Kamal-Uddin, Jess Fitzsimmons); and Whittington Hospital (Sheikh Pahary, Kerry Robinson).

Contributors The study was conceived by DPI, MJP, MDL, PM, DAH, KW and KMR. $A C$ and NJ provided parental input. The pilot trial was conducted and analysed by PM, RC, ZZ, DAH, KMR and DPI. RC was the trial manager and DPI was the chief investigator. The qualitative work was conducted and analysed by $\mathrm{CO}^{\prime} \mathrm{H}$ and $\mathrm{KW}$. The paper was drafted by DPI, RC, PM, DAH and CO'H. All authors read and approved the final manuscript.

Funding This study was funded by the NIHR HTA programme (13/04/105)

Disclaimer The views expressed are those of the authors and not necessarily those of the NHS, the NIHR or the Department of Health.

Competing interests None declared.

Patient consent Not required.

Ethics approval Health Research Authority (HRA) approval was given (Integrated Research Application System reference number: 195544; London - Stanmore Research Ethics Committee reference number: 16/LO/0854).

Provenance and peer review Not commissioned; externally peer reviewed.

Data sharing statement The data sets used and/or analysed during the current study are available from the corresponding author on reasonable request.

Open access This is an open access article distributed in accordance with the Creative Commons Attribution 4.0 Unported (CC BY 4.0) license, which permits others to copy, redistribute, remix, transform and build upon this work for any purpose, provided the original work is properly cited, a link to the licence is given, and indication of whether changes were made. See: https://creativecommons.org/ licenses/by/4.01.

\section{REFERENCES}

1 Brierley J, Carcillo JA, Choong K, et al. Clinical practice parameters for hemodynamic support of pediatric and neonatal septic shock: 2007 update from the American College of Critical Care Medicine. Crit Care Med 2009;37:666-88.

2 Carcillo JA, Davis AL, Zaritsky A. Role of early fluid resuscitation in pediatric septic shock. JAMA 1991;266:1242-5.

3 Booy R, Habibi P, Nadel S, et al. Reduction in case fatality rate from meningococcal disease associated with improved healthcare delivery. Arch Dis Child 2001;85:386-90.

4 Han YY, Carcillo JA, Dragotta MA, et al. Early reversal of pediatric-neonatal septic shock by community physicians is associated with improved outcome. Pediatrics 2003:112:793-9.

5 Inwald DP, Tasker RC, Peters MJ, et al. Emergency management of children with severe sepsis in the United Kingdom: the results of the Paediatric Intensive Care Society sepsis audit. Arch Dis Child 2009:94:348-53.
6 Maitland K, Kiguli S, Opoka RO, et al. Mortality after fluid bolus in African children with severe infection. N Engl J Med 2011;364:2483-95.

7 Hilton AK, Bellomo R. A critique of fluid bolus resuscitation in severe sepsis. Crit Care 2012;16:302.

8 Myburgh J, Finfer $S$. Causes of death after fluid bolus resuscitation: new insights from FEAST. BMC Med 2013:11:67.

9 Cvetkovic M, Lutman D, Ramnarayan P, et al. Timing of death in children referred for intensive care with severe sepsis: implications for interventional studies. Pediatr Crit Care Med 2015;16:410-7.

10 Inwald DP, Butt W, Tasker RC. Fluid resuscitation of shock in children: what, whence and whither? Intensive Care Med 2015;41:1457-9.

11 Flori HR, Church G, Liu KD, et al. Positive fluid balance is associated with higher mortality and prolonged mechanical ventilation in pediatric patients with acute lung injury. Crit Care Res Pract 2011;2011:1-5.

12 Valentine SL, Sapru A, Higgerson RA, et al. Fluid balance in critically ill children with acute lung injury. Crit Care Med 2012;40:2883-9.

13 Sinitsky L, Walls D, Nadel S, et al. Fluid overload at 48 hours is associated with respiratory morbidity but not mortality in a general PICU: retrospective cohort study. Pediatr Crit Care Med 2015;16:205-9.

14 Bhaskar P, Dhar AV, Thompson M, et al. Early fluid accumulation in children with shock and ICU mortality: a matched case-control study. Intensive Care Med 2015;41:1445-53.

15 O'Hara CB, Canter RR, Mouncey PR, et al. A qualitative feasibility study to inform a randomised controlled trial of fluid bolus therapy in septic shock. Arch Dis Child 2018;103:28-32.

16 Lyttle MD, O'Sullivan R, Hartshorn S, et al. Pediatric Emergency Research in the UK and Ireland (PERUKI): developing a collaborative for multicentre research. Arch Dis Child 2014;99:602-3.

17 Woolfall K, Frith L, Gamble C, et al. How parents and practitioners experience research without prior consent (deferred consent) for emergency research involving children with life threatening conditions: a mixed method study. BMJ Open 2015;5:e008522.

18 Molyneux S, Njue M, Boga M, et al. 'The words will pass with the blowing wind': staff and parent views of the deferred consent process, with prior assent, used in an emergency fluids trial in two African hospitals. PLoS One 2013:8:e54894.

19 Woolfall K, Frith L, Gamble C, et al. How experience makes a difference: practitioners' views on the use of deferred consent in paediatric and neonatal emergency care trials. BMC Med Ethics 2013;14:45.

20 Woolfall K, Frith L, Dawson A, et al. Fifteen-minute consultation: an evidence-based approach to research without prior consent (deferred consent) in neonatal and paediatric critical care trials. Arch Dis Child Educ Pract Ed 2016:101:49-53.

21 Maitland K, Molyneux S, Boga M, et al. Use of deferred consent for severely ill children in a multi-centre phase III trial. Trials 2011;12:90.

22 Brierley J, Larcher V. Emergency research in children: options for ethical recruitment. J Med Ethics 2011:37:429-32.

23 Jansen TC, Kompanje EJ, Bakker J. Deferred proxy consent in emergency critical care research: ethically valid and practically feasible. Crit Care Med 2009;37:S65-S68.

24 Slater A, Shann F, Pearson G. Paediatric Index of Mortality (PIM) Study Group. PIM2: a revised version of the Paediatric Index of Mortality. Intensive Care Med 2003:29:278-85.

25 Annual report of the paediatric intensive care audit network. Leeds: University of Leeds and University of Leicester, 2016.

26 Sim J, Lewis M. The size of a pilot study for a clinical trial should be calculated in relation to considerations of precision and efficiency. J Clin Epidemiol 2012;65:301-8.

27 Tong A, Sainsbury P, Craig J. Consolidated criteria for reporting qualitative research (COREQ): a 32-item checklist for interviews and focus groups. Int I Qual Health Care 2007;19:349-57.

28 Onwuegbuzie AJ, Leech NL. On Becoming a pragmatic researcher: the importance of combining quantitative and qualitative research methodologies. Int I Soc Res Methodol 2005:8:375-87.

29 Boeije H. A purposeful approach to the constant comparative method in the analysis of qualitative interviews. Quality and Quantity 2002;36:391-409.

30 Davis AL, Carcillo JA, Aneja RK, et al. Clinical practice parameters for hemodynamic support of pediatric and neonatal septic shock. Crit Care Med 2017;45:1061-93.

31 Martinón-Torres F, Salas A, Rivero-Calle I, et al. Life-threatening infections in children in Europe (the EUCLIDS Project): a prospective cohort study. Lancet Child Adolesc Health 2018:2:404-14.

32 Parikh SR, Andrews NJ, Beebeejaun K, et al. Effectiveness and impact of a reduced infant schedule of $4 C M e n B$ vaccine against group $B$ meningococcal disease in England: a national observational cohort study. Lancet 2016;388:2775-82.

33 Public Health England. Immunisation against infectious disease and Children's Health 2013.

34 Gelbart B, Glassford NJ, Bellomo R. Fluid bolus therapy-based resuscitation for severe sepsis in hospitalized children: a systematic review. Pediatr Crit Care Med 2015:16:e297-307.

35 Santhanam I, Sangareddi S, Venkataraman S, et al. A prospective randomized controlled study of two fluid regimens in the initial management of septic shock in the emergency department. Pediatr Emerg Care 2008:24:647-55. 